\title{
Relatives' views on involuntary hospital admission in 8 EUNOMIA sites
}

\author{
Andrea Fiorillo*1, Corrado de Rosa ${ }^{1}$, Flavia Rossano ${ }^{1}$, Lorenza Magliano ${ }^{1}$, \\ Mario Maj ${ }^{1}$, Thomas Kallert ${ }^{2}$, Georgi Onchev ${ }^{3}$, Jiri Raboch ${ }^{4}$, \\ Anastasia Karastergiou ${ }^{5}$, Andrzej Kiejna ${ }^{6}$, Petr Nawka ${ }^{7}$ and Lars Kjellin ${ }^{8}$
}

\begin{abstract}
Address: ${ }^{1}$ Department of Psychiatry, University of Naples SUN, Largo Madonna delle Grazie, I-80138 Naples, Italy, ${ }^{2}$ Dresden University of Technology, Faculty of Medicine, Department of Psychiatry and Psychotherapy, Fetscherstrasse 74, D-01307 Dresden, Germany, ${ }^{3}$ Department of Psychiatry, Medical University of Sofia, St G. Sofiisky str. 1, 1431 Sofia, Bulgaria, ${ }^{4}$ Psychiatric Department, 1st Medical School of Charles University, Ke Karlovu 11, 2, 12801 Prague, Czech Republic, 5Psychiatric Hospital of Thessaloniki, 196, Lagada Street, 56430 Thessaloniki, Greece, ${ }^{6}$ Department of Psychiatry, Medical University, Pasteura 10, 50-367 Wroclaw, Poland, 7Psychiatrica nemocnica, Stranany, 07101 Michalovce, Slovakia and ${ }^{8}$ Psychatric Research Center, P.O. Box 1613, SE-701 Orebro, Sweden

* Corresponding author
\end{abstract}

from WPA Thematic Conference. Coercive Treatment in Psychiatry: A Comprehensive Review Dresden, Germany. 6-8 June 2007

Published: 19 December 2007

BMC Psychiatry 2007, 7(Suppl I):S32 doi:10.1 I86/147I-244X-7-SI-S32

This abstract is available from: http://www.biomedcentral.com/I47I-244X/7/SI/S32

(c) 2007 Fiorillo et al; licensee BioMed Central Ltd.

\section{Objectives}

This study aimed to: a) describe the opinions of relatives of mentally ill patients about treatments and procedures adopted during a psychiatric admission; b) explore differences in the opinions among relatives living in 8 different European countries.

\section{Methods}

Data have been collected on a sample of relatives of patients involuntarily hospitalized in 8 European countries (Germany, Bulgaria, Czech Republic, Greece, Italy, Poland, Slovakia, Sweden) from the EUNOMIA network. Relatives' opinions on treatments and procedures received by their mentally ill relatives during the reference hospitalization's period have been explored by ad-hoc schedules.

\section{Results}

Relatives were overall satisfied with treatment provided to patients during the current hospitalization. Significant differences have been detected among the centers as concerns relatives' perceived pressure at patients' admission, satisfaction with treatments provided to hospitalized patients, and opinions about the usefulness of treatments and procedures adopted in emergency situations. In par- ticular, Bulgarian relatives reported the highest levels of pressure at patients' admission, and Italian relatives largely disagreed with the possibility to admit psychiatric patients in asylums (as forbidden in Italy since 1978).

\section{Conclusion}

The differences in the relatives' opinions found in this study are likely to be influenced by cultural factors and national mental health policies. These differences are likely to influence mental health care practices in European countries, and should be taken into account in order to develop common European guidelines for psychiatric treatments. 